\title{
Risk factors for presbycusis in a socio-economic middle-class sample
}

\author{
Cláudia Simônica de Sousa ${ }^{1}$, Ney de Castro \\ Júnior ${ }^{2}$ Erkki Jubani Larsson ${ }^{3}$, Ting Hui Ching ${ }^{4}$
}

Keywords: risk factors, sensorineural hearing loss, presbycusis.

\section{Summary}

\begin{abstract}
$\mathrm{P}$ bycusis, or the aging ear, involves mainly the inne ear and the cochlear nerve, causing sensorineural hearing loss. Risk factors include systemic diseases and poor habits that cause inner ear damage and lead to presbycusis. Correct identification of these risk factors is relevant for prevention. Aim: To evaluate the prevalence and to identify the risk factors of presbycusis in a sample aged over 40 years. Study design: a retrospective case series. Subjects and Methods: medical records of 625 patients were evaluated. Presbycusis was identified using pure tone audiometry, speech audiometry and impedance testing of all patients. Results: The prevalence of presbycusis was 36.1\%; the mean age was 50.5 years ranging from 40 to 86 years; $85.5 \%$ were male and $14.5 \%$ werf female. Age, the male gender, diabetes mellitus, and hereditary hearing loss were identified as risk factors. Cardiovascular diseases, smoking and consumption of alcohol were not confirmed as risk factors, although these have often been mentioned as risk factors for presbycusis. Conclusion: Notwithstanding the idea that presbycusis has multiple risk factors, this study identified few risk factors for this disease.
\end{abstract}




\section{INTRODUCTION}

Presbycusis (from the Greek prébys = aged, and ákousis $=$ hearing) refers to age-related hearing $\operatorname{loss}^{1}$ with no apparent cause. The term elderly or aged refers to persons aged 60 years or above, as defined by the World Health Organization (WHO) in $1984 .^{2}$ The Brazilian Geographical and Statistical Institute (Instituto Brasileiro de Geografia e Estatística or IBGE) defines a middle social and economical class as that with a mean monthly income of seven to 15 Brazilian minimum salaries. ${ }^{3}$

According to the IBGE, the number of people aged over 60 years went from three million in 1960 to seven million in 1975 and to 14 million in 2002; this is a $500 \%$ increase over a 40-year period. Each year, an extra 650 thousand elderly people are added to the Brazilian population. ${ }^{2,4}$ Projections for 2024 suggest that there will be 32 million elderly persons in Brazil, about $15 \%$ of the population; this places Brazil in sixth place in the world classification of countries with the largest populations of elderly persons. ${ }^{4}$ There have been few epidemiological studies on the prevalence of presbycusis in Brazil.5,6

Presbycusis is characterized histopathologically by lesions in the inner ear and cochlear nerve, and functionally by sensorineural hearing loss. ${ }^{7,8}$ It starts in the fifth decade of life and is currently considered as the most frequent cause of adult hearing loss; ${ }^{1,9}$ thus, the onset of auditory system degeneration starts before the beginning of elderly age. The resulting communication difficulties, social withdrawal, depression and decreased quality of life cause significant health issues, and weigh significantly on the public health system. ${ }^{2}$

Risk factors such as systemic disease and poor habits add to presbycusis. According to the literature, risk factors are the male gender, smoking, noise exposure during leisure, stress, metabolic and vascular conditions (diabetes, dyslipidemias, systemic arterial hypertension, atherosclerosis, low encephalic output) and heredity.,7 The association between presbycusis and these risk factors, however, remains controversial and has not been well established. Nevertheless, these factors should be noted to eventually attenuate or prevent the effects of presbycusis.

\section{OBJECTIVE}

The purpose of this study was to assess the prevalence of presbycusis and to correlate possible risk factors in a population sample aged 40 years and above, with or with no complaints of hearing loss.

\section{SERIES AND METHOD}

An observational cross-sectional study with a sequential sample was undertaken of data gathered from the files of patients of both sexes aged 40 years and above at a check-up unit of Hospital X from January 2001 to August 2005. The Research Ethics Committee of the institution approved the study (protocol number $16 / 03$ of $08 / 12 / 2003)$.

Patients undergoing check-up exams and evaluations at this unit generally have a university undergraduate degree and work in medium-sized and major companies; their income places them among the Brazilian middle to high social/economic class.

Based on inclusion and exclusion criteria, 625 files were selected.

\section{Inclusion criteria:}

1. Subjects aged 40 years or over.

2. No vestibular complaints and no history of otological surgery.

3. Normal hearing characterized as:

a. Pure tone thresholds (air conduction) over 25

dBHL at $250 \mathrm{~Hz}$ to $8 \mathrm{kHz}$

b. Type A (Jerger) tympanometric curve.

4. Sensorineural hearing loss with a diagnosis of presbycusis according to:

a. Bilateral and symmetrical hearing loss.

b. Pure tone thresholds decreasing beyond 26

dBHL at least at $2 \mathrm{kHz}$ to $8 \mathrm{kHz}$ (flat or descending). 10

c. Type A (Jerger) tympanometric curve.

\section{Exclusion criteria:}

1. Outer and/or middle ear disease.

2. Sensorineural hearing loss, with a clear cause other than presbycusis.

3. Patients working in noisy environments without adequate auditory protection.

A form generated by the main researcher established the data to be gathered from the files. The risk factors that were investigated were: sex, age, profession, diabetes mellitus, dyslipidemias (cholesterol and triglyceride levels), arterial hypertension, long-term use of medication, use of hormones, alcohol consumption (two or more times a week), smoking, a genetic history of age-related or idiopathic hearing loss.

Patients went through a check-up routine including otorhinolaryngological and audiological evaluations, laboratory exams, and clinical assessments of other medical specialties. The otorhinolaryngological exam (ENT) consisted of a physical examination and an audiological 
investigation. The same professionals (two physicians and two speech therapists) carried out the exams.

Speech therapists conducted standard voice and pure tone audiometry and immittance testing in an acoustic booth. ${ }^{11}$ An Interacoustics AC5 audiometer with TDH 19 headphones was used for voice and pure tone audiometry; an Interacoustics AZ7 device was used for acoustic immittance testing. These devices are calibrated annually.

Audiometry results were classified as normal or presbyacustic, regardless of the degree of hearing loss. Bivariate statistical analysis was used for testing the variables, evaluating the relation between presbycusis and possible associated risk factors.

Age was divided into six age groups: 40 to 45 years, 46 to 50 years, 51 to 55 years, 56 to 60 years, 61 to 65 years, and over age 65 years.

Two groups of professionals were established: engineers and others. Most of the sample consisted of engineers, which explained this division; there were a few other professions represented.

The chi-square statistical test was done to study the association among qualitative variables; the results of audiometric tests (outcome) and the Kruskal-Wallis nonparametric test were used for comparing the distribution of quantitative variables in altered audiometric tests. The significance level (p) was 5\%.

The linear logistical regression model (multivariate analysis) was used for selecting those variables that best explained hearing loss. Variables with $p<0.20$ in the bivariate analysis were used in the initial model. The backward method (Wald) was used for variable selection. The adjusted odds ratio (OR) of variables comprising the final model and their 95\% confidence intervals (CI) were calculated.

The SPSS for Windows software, version 13.0, was used in this study.

\section{RESULTS}

Files of male patients comprised 534 (85.4\%) of 625 files. Presbycusis was found in 226 (36.1\%) of these cases. The mean age in the sample was 50.5 years (SD - 6.7 years); the youngest patient was aged 40 years and the eldest, 86 years. Table 1 shows the social and demographic features of the sample and the distribution according to the chi-square test. The variables sex and age range were statistically significant $(p<0.05)$; the variable profession was not statistically associated with Presbycusis.

Table 2 shows the relation between clinical data and Presbycusis; the chi-square test revealed a positive statistical significance for the variables diabetes mellitus and a family history of hearing loss. There were nonsignificant associations with the variables: consumption of alcohol, smoking, a family history of dyslipidemia, systemic arterial hypertension, use of hormones, use of medication continuously, and other diseases.

There was no statistically positive association between the lipid profile and Presbycusis (Table 3).

The variables selected for the logistics regression model were those associated with Presbycusis in this sample. Table 4 shows that the female sex is a protective factor against hearing loss $(\mathrm{OR}<1)$. Subjects aged over 50 years had a higher risk of Presbycusis, as did subjects with diabetes mellitus and a positive family history of hearing loss.

Table 1. Social and demographic features of the sample and the audiometric profile.

\begin{tabular}{|c|c|c|c|c|c|c|}
\hline \multirow{3}{*}{ Variable } & & \multicolumn{5}{|c|}{ Audiometric Profile } \\
\hline & & \multirow{2}{*}{$\frac{\text { Normal }}{\mathrm{N}}$} & \multicolumn{3}{|c|}{ Presbycusis } & \multirow[t]{2}{*}{$\mathrm{p}^{*}$} \\
\hline & & & $\%$ & $\mathrm{~N}$ & $\%$ & \\
\hline \multirow{2}{*}{ Sex } & male & 327 & 82 & 207 & 91,6 & 0,001 * \\
\hline & female & 72 & 18 & 19 & 8,4 & \\
\hline \multirow{6}{*}{ Age group } & $40-45$ & 92 & 23,1 & 22 & 9,7 & $0^{*}$ \\
\hline & $46-50$ & 131 & 32,8 & 47 & 20,8 & \\
\hline & $51-55$ & 119 & 29,8 & 67 & 67 & \\
\hline & $56-60$ & 46 & 11,5 & 56 & 24,8 & \\
\hline & $61-65$ & 6 & 1,5 & 17 & 7,5 & \\
\hline & over 65 & 5 & 1,3 & 17 & 7,5 & \\
\hline \multirow{2}{*}{ Profession } & Engineer & 130 & 32,6 & 71 & 31,4 & 0,764 \\
\hline & Others & 269 & 67,4 & 155 & 68,6 & \\
\hline Sub-total & 399 & & 226 & & & \\
\hline
\end{tabular}


Table 2. Results of clinical data and the audiometric profile.

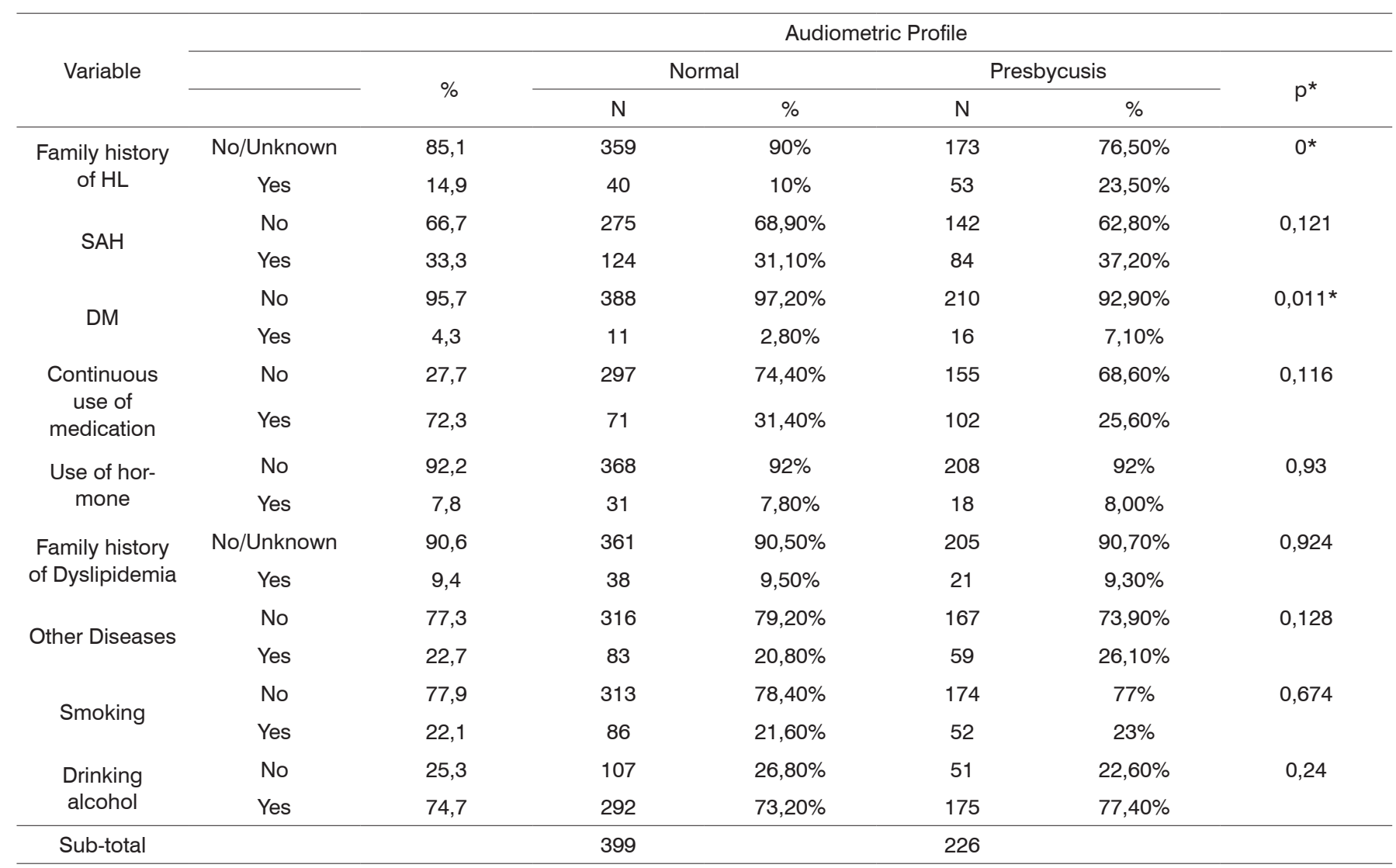

$p^{*}$ : significance level of the chi-square test.

Table 3. Results of the lipid profile and the audiometric profile.

\begin{tabular}{ccccc}
\hline \multirow{2}{*}{ Variable } & \multicolumn{3}{c}{ Audiometric Profile } & \multirow{2}{*}{$\mathrm{p}^{*}$} \\
\cline { 2 - 4 } & Normal & Altered & Total & \\
\hline TG & 345 & 215 & 560 & 0,086 \\
Total cholestero & 345 & 214 & 559 & 0,623 \\
LDL - cholesterol & 337 & 208 & 545 & 0,966 \\
\hline
\end{tabular}

$\mathrm{p}$ *: significance level of the Kruskal-Wallis non-parametric test.

Table 5 shows the results of the logistics regression model. A comparison between the prediction of the model and the audiometric profile in the sample revealed that the correctness percentage for patients having normal audiometric profiles was $80.3 \%$, and $50.7 \%$ for patients having altered audiometric profiles. The total correctness percentage was $68.9 \%$.

\section{DISCUSSION}

According to histopathological studies, the onset of Presbycusis occurs in the fifth decade of life. ${ }^{7,8}$ The WHO has defined elderly as persons reaching or surpassing the seventh decade of life. ${ }^{2}$ The purpose of this study was to assess the risk factors of Presbycusis; thus, the age groups were established based on histopathological studies of the aging auditory system, ${ }^{7,8}$ comprising subjects from the fifth decade onwards.

Presbycusis is a multifactor process in which there is wide individual variation in the expression of each factor; the literature agrees on this fact.

The prevalence of Presbycusis was 36.1\% in the sample. Published hearing loss prevalence values have ranged from $5 \%$ to $71.8 \% ; 5,12$ population based epidemiological studies have indicated prevalence values from 20 to $40 \% .13,14$ This variation in the literature is due mostly to variations in the method for detecting Presbycusis, which ranged from simple questionnaires to full audiological assessments. 
Table 4. Variables selected in the logistics regression model and the results.

\begin{tabular}{|c|c|c|c|c|c|}
\hline \multirow{2}{*}{ Variable } & & \multirow{2}{*}{$\mathrm{p}^{*}$} & \multirow{2}{*}{$\mathrm{OR}^{\star \star}$} & \multicolumn{2}{|c|}{$95,0 \% \mathrm{Cl}^{\star \star *}$} \\
\hline & & & & Lower & Higher \\
\hline Sex & Female & $0,003^{*}$ & 0,286 & 0,22 & 0,727 \\
\hline \multirow[t]{6}{*}{ Age group } & $40-45$ & reference & & & \\
\hline & $46-50$ & 0,321 & 1,367 & 0,738 & 2,535 \\
\hline & $51-55$ & $0^{*}$ & 1,953 & 1,07 & 3,564 \\
\hline & $56-60$ & $0^{*}$ & 3,677 & 1,908 & 7,089 \\
\hline & $61-65$ & $0^{*}$ & 10,851 & 3,441 & 34,213 \\
\hline & over 65 & 0 * & 12,217 & 3,875 & 38,519 \\
\hline Family history of $\mathrm{HL}$ & Yes & $0^{*}$ & 3,098 & 1,853 & 5,18 \\
\hline DM & Yes & 0,93 & 2,12 & 0,883 & 5,088 \\
\hline
\end{tabular}

$p^{*}$ significance level of the backward method (Wald).

$\mathrm{OR}^{\star *}$ odds ratio $<1$.

$\mathrm{Cl}^{\star * *}$ confidence interval.

Table 5. Sensitivity and specificity of the inferred model.

\begin{tabular}{lccc}
\hline Audiometric profile & Normal & Presbycusis & \% correctness \\
\hline Normal & 277 & 68 & 80,3 \\
Presbycusis & 106 & 109 & 50,7 \\
\hline \% Correctness & & & 68.9 \\
\hline
\end{tabular}

Family income ${ }^{15}$ and the education level may be inversely proportional to the prevalence of Presbycusis. In the Brazilian study that presented a $71.8 \%$ prevalence - the highest found in our review - the sample consisted of a low income (one to two minimum salaries - $44.7 \%$ of the sample) and poorly educated population that was at a higher risk for poor health. ${ }^{5}$ Our results suggest that a sample of better educated and wealthier subjects - which have more access to information and health services - may control more adequately the risk factors for Presbycusis.

The method comprised a sample aged from the fifth decade onwards; according to the literature this is the age range in which Presbycusis occurs. The correlation between increasing age and a growing prevalence of Presbycusis was statistically significant, and conforms with published data. ${ }^{16-18}$

The sample consisted mostly of male subjects (85.4\%), due to its demographic features: professionals in managerial jobs or directors of mid-sized and large companies; there are fewer women in these functions. The male gender was associated with Presbycusis in our study; this conclusion is reflected in other citations, wherein male subjects are at a higher risk for developing Presbycusis at a younger age. ${ }^{6,14,17-19}$ This statement is, however, still an open issue; some references in the literature have suggested that the female gender is a risk factor for Presbycusis. ${ }^{5,18}$ Two papers concluded that there was not association between gender and Presbycusis. ${ }^{17,20}$

The percentage of engineers in our sample (47.40\%) stimulated an investigation of this profession as a risk factor for Presbycusis, given the features of this activity. Subjects may be exposed to unhealthy environments from an auditory standpoint, which could lead to Presbycusis. There was, however, no positive association between engineering and Presbycusis. The explanation may be that most of the engineers in this sample were exposed to noisy environments for short periods and routinely used individual protection equipment (earplugs and/or earmuffs). A positive correlation between hearing loss and certain professions is frequent, although not necessarily characterized as noise-induced hearing loss. ${ }^{14,21}$

Findings in this study suggest a positive association between diabetes mellitus and Presbycusis; the type of diabetes was not specified. This association is wellknown and generally accepted; ${ }^{15,22}$ some researchers, however, have question this correlation. ${ }^{5,21}$ Hearing loss in some forms of type I diabetes mellitus results from the inherited mitochondrial phenotype plus the effect of dysglycemia on the inner ear. ${ }^{23}$

Systemic arterial hypertension is often associated with Presbycusis, ${ }^{12,24}$ although a consensus is lacking since many studies have not established this correlation; ${ }^{5,15,21}$ this may be due to medical treatment of this condition. We found no association between systemic arterial hypertension and Presbycusis.

We also found no positive association between dyslipidemia and Presbycusis, a common finding in the 
literature. ${ }^{24-26}$ Some authors, however, have suggested that this association depends on the severity and duration of dyslipidemia. ${ }^{12,27}$

Hormone replacement therapy (progesterone and/ or estrogen) has been suggested as a risk factor for Presbycusis. ${ }^{28,29}$ We found no relation between Presbycusis and hormone replacement therapy, which might be due to the size of the sample.

Our results revealed no correlation between smoking/alcohol consumption and Presbycusis. These habits were coded qualitatively as present or absent in our questionnaire; there was no information about the duration and intensity of these habits. Some papers have raised the possibility of an association between smoking and Presbycusis, ${ }^{30,31,32}$ while others have not confirmed this correlation. ${ }^{5,15,24}$

There was a positive association between Presbycusis and a family history of this condition, which is a consensus in the literature. Genome studies have found $\mathrm{X}$-linked probably mitochondrial genic loci affecting male subjects. 33,34

\section{CONCLUSION}

A study of risk factors for Presbycusis in social/ economic middle-class subjects revealed that:

1. The prevalence of Presbycusis was 36.1\%.

2. There were statistically positive associations between Presbycusis and: age, the male gender, diabetes mellitus and a family history of Presbycusis.

3. There was not association between Presbycusis and: profession, systemic arterial hypertension, dyslipidemia (triglycerides, total cholesterol, and low-density lipoprotein), a family history of dyslipidemia, and smoking or drinking alcoholic beverages.

4. Results show that although there are multiple risk factors for Presbycusis listed in the literature, these factors were limited in our sample.

\section{REFERENCES}

1. Koopmann Jr,CF. Problemas otolaringológicos no idoso. Med Clin North Am. 1991;6:1411-27.

2. Veras R. A longevidade da população: desafios e conquistas. Rev Serv Soc e Sociedade. 2003;75:5-18.

3. Lobato J. A classe média no fundo do poço. Ciência hoje online de 01/06/04. Disponível em: http://cienciahoje.uol.com.br/ controlPanel/materia/view $/ 2478$

4. Instituto Brasileiro de Geografia e Estatística. Síntese dos indicadores sociais 2000. Rio de Janeiro: IBGE; 2001.

5. Viude A. Fatores associados a presbiacusia em idosos.Tese de Doutorado-USP-SP. 2002.120p.

6. Mattos LC, Veras RP. Prevalência da perda auditiva em uma população de idosos da cidade do Rio de Janeiro: um estudo seccional. Rev Bras Otorrinolaringol. 2007;73:654-9.
7. Schuknecht HF. Pathology of the ear. 2nd ed. Cambridge, Ma. Harvard University Press. 1974. 503p.

8. Schuknecht HF, Gacek MR. Cochlear pathology in presbycusis. Ann Otol Rhinol Laryngol. 1993:102:1-16.

9. Raul H, Ralph FN. Presbycusis. In: Paparella MM, Shumrick DA, Gluckman JL, Meyerhoff WL, editors. Tratado de Otorrinolaringologia. 3a ed. Buenos Aires: Panamericana;1994. p. 1906-17.

10. Cruz Fo NA, Breuel MLF, Campilongo, M. Presbiacusia. In Campos CAH, Costa HOO. Editores. Tratado de Oto Rino Laringologia: $1^{\underline{a}}$ Ed. S. Paulo: Roca; 2003.V2. p.186-92.

11. Redondo MC, Lopes Fo OC. Testes básicos de avaliação auditiva. In Lopes Fo OC. Editor. Tratado de Fonoaudiologia. $1^{\underline{a}}$ Ed. S. Paulo: Roca; 1997. p.83-108.

12. Lim DP, Stephens SDG. Clinical investigation of hearing loss in the elderly. Clin Otolaryngol. 1991;16:288-93.

13. Sindhusake D, Mitchell P, Smith W, Golding M, Newall P, Hartley D, et al. Validation of self-reported hearing loss. The Blue Mountains Hearing Study. Int J Epidemiol. 2001;30:1371-8.

14. Cruickshanks KJ, Wiley TL, Tweed TS, Klein BEK, Klein R, MaresPerlman JA, et al. Prevalence of hearing loss in older adults in Beaver Dam, Wisconsin. The Epidemiology of Hearing Loss Study. Am J Epidemiol. 1998;148:879-86.

15. Cruickshanks KJ, Tweed TS, Wiley TL, Klein BEK, Klein R, Chappell $\mathrm{R}$ et al. The 5-year incidence and progression of hearing loss. Arch Otolaryngol Head Neck Surg. 2003;129:1041-6.

16. Jonsson R, Rosenhall U. Hearing in advanced age. A study of Presbycusis in 85, 88, and 90 year-old people. Audiology. 1998;37: 207-18.

17. Wilson DH, Walsh PG, Sanchez L, Davis AC, Taylor AW, Tucker G, et al. The epidemiology of hearing impairment in an Australian adult population. Int J Epidemiol. 1999;28:247-52.

18. Megighian D, Savastano M, Salvador L, Frigo A, Bolzan M. Audiometric and epidemiological analysis of elderly in the Veneto region. Gerontology. 2000;46:199-204.

19. Baraldi GS; Almeida LC; Borges ACC. Evolução da perda auditiva no decorrer do envelhecimento. Rev Bras Otorrinolaringol. 2007;73:64-70.

20. Katsarkas A, Ayukawa H: Hearing loss due to aging (presbyacusis). J Otolarygol. 1986;15:239-44.

21. Rey JF, Castro-Morello G, Curto JLB. Factores de riesco involucrados en la presbiacusia. Acta Otorrinolaringol. Esp 2002;53:572-7.

22. Marchiori LLM, Gibrin PCD. Diabetes melito: prevalência de alterações auditivas. Arq Bras Endocrinol Metab. 2003;47:82-6.

23. Scala WAR Caracterização clínica e epidemiológica dos portadores de diabetes melito e surdez de herança materna determinados pela mutação mitocondrial A324G no gene RNALeu(URR).Tese de Mestrado - Otorrinolaringologia. FCM da Sta. Casa de S. Paulo, 2006.

24. Gates AG, Cobb JL, D'Agostino RB, Wolf PA. The relation of hearing in the elderly to the presence of cardiovascular disease and cardiovascular risk factors. Arch Otolaryngol Head Neck Surg. 1993;119:156-61.

25. Jones NS, Davis A. A prospective case-controlled study of patients presenting with idiopatic sensorioneural hearing loss to examine the relationship between hyperlipidaemia and sensorioneural hearing loss. Clin Otolaryngol 1999;24:531-6.

26. Evans MB, Oghalai SJ, Shope C, Brownell WE. Dyslipidemia and cochlear function. Otolaryngol Head Neck Surg 2004;131:151-2.

27. Villares CM, Carbajo JSR, Calvo JD, Pello MEF. Perfil lipídico de la sordera ligada al envejecimiento. Nutr Hosp 2005;20:52-7.

28. Kim SH, Kang BM,Chae HD, Kim CH. The Association Bethween Serum Estradiol Level and Hearing Sensitivity in Postmenopausal Women. Obstetrics and Gynecology 2002;5:726-30. 
29. Guimarães P, Frisina ST, Mapes F, Tadros SF, Frisina DR, Frisina RD. Progestin negatively affects hearing in aged women. PNAS 2006;(103)38:14246-9.

30. Cruickshanks KJ, Klein R, Klein BEK, Wiley TL, Nondahl DM, Tweed TS. Cigarette smoking and hearing loss: the epidemiology of hearing loss study. JAMA 1998;279:1715-9.

31. Nondahl DM, Cruickshanks KJ, Dalton DS, Schubert CR, Klein BEK, Klein R, et al. Serum nicotine level and incident hearing loss. Arch Otolaryngol Head Neck Surg 2004;130:1260-4.
32. Rosenhall U, Sixt E, Sundh V, Svanborg A. Correlations between Presbycusis and extrinsic noxious factors. Audiology 1993;32:23443.

33. DeStefano AL, Gates GA, Heard-Costa N, Myers RH, Baldwin CT. Genomewide linkage analysis to Presbycusis in the Framinghan heart study. Arch Otolaryngol Head Neck Surg 2003;129:285-9.

34. Garringer HJ, Pankratz ND, Nichols WC, Reed T. Hearing impairment susceptibility in elderly men and the DFNA18 locus. Arch Otolaryngol Head Neck Surg 2006;132:506-10. 